\title{
Qualidade higiênico-sanitária de alimentos consumidos em embarcações fluviais no
}

\author{
Amazonas \\ Hygienic-sanitary quality of food consumed on river vessels in the Amazonas \\ Calidad higiénico-sanitaria de los alimentos consumidos en embarcaciones fluviales en el Amazonas
}

Recebido: 27/05/2021 | Revisado: 20/06/2021 | Aceito: 28/07/2021 | Publicado: 04/08/2021

Kayanne Dantas de Souza

ORCID: https://orcid.org/0000-0003-2255-1260 Universidade Federal do Amazonas, Brasil

E-mail: kayanne_rk15@outlook.com

Carolina Arruda de Faria

ORCID: https://orcid.org/0000-0001-8086-1262

Universidade Federal do Amazonas, Brasil

E-mail: cafaria@ufam.edu.br

Amanda Forster Lopes

ORCID: https://orcid.org/0000-0002-3195-4013 Universidade Federal do Amazonas, Brasil

E-mail: amandalopes@ufam.edu.br

Michel Nasser Corrêa Lima Chamy

ORCID: https://orcid.org/0000-0003-3528-2717

Universidade Federal do Amazonas, Brasil E-mail: clchamy@ufam.edu.br

\begin{abstract}
Resumo
Introdução: No norte e nordeste do Brasil, onde localiza-se a região amazônica brasileira, existem altas prevalências de surtos de doenças causadas por micro-organismos patogênicos presentes em alimentos. O armazenamento inadequado destes alimentos é uma das grandes causas de contaminação com consequentes infecções e intoxicações alimentares. Objetivo: Avaliar a qualidade higiênico-sanitária dos alimentos destinados ao consumo em embarcações da linha de navegação Coari-Manaus. Método: Trata-se de uma pesquisa com abordagem quali-quantitativa, com delineamento descritivo-exploratório. Para caracterização microbiológica, foram coletadas amostras de frango, peixe e carne armazenados em duas embarcações, seguida da aplicação do checklist das condições de armazenamento, que forneceu resultados rápidos e confiáveis que permitiram o monitoramento da segurança microbiológica de alimentos. Foram feitas análises de presença dos seguintes micro-organismos: bactérias mesófilas aeróbias, bactérias psicrotróficas, coliformes totais, coliformes termotolerantes, Salmonella, bolores e leveduras. Resultados: As análises das amostras coletadas apresentaram resultados positivos para os microrganismos avaliados, confirmando sua presença nos alimentos armazenados nas embarcações. Conclusão: Os resultados obtidos neste estudo indicam que a intensificação nas fiscalizações nas embarcações ainda se faz necessária, pois as contaminações desses alimentos são de grande risco à saúde dos seres humanos, priorizando-se o monitoramento no local para controle e medidas de prevenção de contaminação a serem adotadas.
\end{abstract}

Palavras-chave: Qualidade microbiológica; Check-list; Doenças transmitidas por alimentos; Agentes patogênicos.

\begin{abstract}
Introduction: In the north and northeast of Brazil, where the Brazilian Amazon region is located, there is a high prevalence of disease outbreaks caused by pathogenic microorganisms present in food. The improper storage of these foods is a major cause of contamination with consequent infections and food poisoning. Objective: To evaluate the hygienic-sanitary quality of food intended for consumption in vessels on the Coari-Manaus shipping line. Method: This is a research with a quali-quantitative approach, with a descriptive-exploratory design. For microbiological characterization, samples of chicken, fish and beef stored in two vessels were collected, followed by the application of the checklist of storage conditions, which provided fast and reliable results that allowed the monitoring of the microbiological safety of food. Analyzes of the presence of the following microorganisms were made: aerobic mesophilic bacteria, psychrotrophic bacteria, total coliforms, thermotolerant coliforms, Salmonella, molds and yeasts. Results: The analyzes of the samples collected showed positive results for the microorganisms evaluated, confirming their presence in the food stored in the vessels. Conclusion: The results obtained in this study indicate that intensification of inspections on vessels is still necessary, as the contamination of these foods is of great risk to the health of human beings, prioritizing on-site monitoring of the measures adopted to control and prevent contamination. Keywords: Microbiological quality; Check list; Foodborne diseases; Pathogenic agents.
\end{abstract}




\begin{abstract}
Resumen
Introducción: En el norte y noreste de Brasil, donde se ubica la región amazónica brasileña, existe una alta prevalencia de brotes de enfermedades causadas por microorganismos patógenos presentes en los alimentos. El almacenamiento inadecuado de estos alimentos es una de las principales causas de contaminación con las consiguientes infecciones e intoxicaciones alimentarias. Objetivo: Evaluar la calidad higiénico-sanitaria de los alimentos destinados al consumo en embarcaciones de la línea naviera Coari-Manaus. Método: Se trata de una investigación con enfoque cualicuantitativo, con un diseño descriptivo-exploratorio. Para la caracterización microbiológica, se recolectaron muestras de pollo, pescado y carne almacenadas en dos recipientes, seguido de la aplicación del checklist de condiciones de almacenamiento, que brindó resultados rápidos y confiables que permitieron el monitoreo de la inocuidad microbiológica de los alimentos. Se realizaron análisis de la presencia de los siguientes microorganismos: bacterias mesófilas aerobias, bacterias psicrotróficas, coliformes totales, coliformes termotolerantes, Salmonella, mohos y levaduras. Resultados: Los análisis de las muestras recolectadas arrojaron resultados positivos para los microorganismos evaluados, confirmando su presencia en los alimentos almacenados en los recipientes. Conclusión: Los resultados obtenidos en este estudio indican que aún es necesaria la intensificación de las inspecciones en los buques, ya que la contaminación de estos alimentos es de gran riesgo para la salud de los seres humanos, priorizando el monitoreo in situ de las medidas adoptadas para controlar y prevenir contaminación.
\end{abstract}

Palabras clave: Calidad microbiológica; Lista de verificación; Enfermedades transmitidas por los alimentos; Agentes patógenos.

\title{
1. Introdução
}

$\mathrm{Na}$ Amazônia, as cidades, em sua maioria, são interligadas por rios pelas suas características geográficas. Consequentemente, possuem como principal meio de transporte as embarcações mistas, que consistem em barcos de madeira ou ferro, que transportam cargas e passageiros oferecendo um transporte seguro e com baixo custo. Dentre a grande variedade de cargas transportadas via fluvial, estão incluídos os alimentos perecíveis e não perecíveis. As viagens têm duração média de $12 \mathrm{~h}$ entre a maioria das cidades do interior e a capital do Estado, Manaus, e por isso faz-se necessário a oferta de refeições durante a viagem, o que merece destaque uma vez que as normas de transporte, armazenamento e preparo de alimentação podem não ser seguidas, devido, entre outros fatores, à estrutura de armazenamento das embarcações (Soares et al., 2017).

No Brasil foram notificados, entre os anos de 2000 a 2017, 12.503 surtos de Doenças Transmitidas por Alimentos DTA. Dentre esses, 3.196 foram confirmados em laboratório, e, 92,2\% do total de 2.593 casos, cuja identificação do agente etiológico foi realizada, ocorreram devido a patógenos de origem bacteriana (Brasil, 2018). No estado do Maranhão, no período de 2007 a 2019, sabe-se que foram relatados um total de 48 surtos de doenças causadas por micro-organismos patogênicos presentes em alimentos (Souza et al., 2021).

$\mathrm{O}$ armazenamento adequado assim como a temperatura ideal são fatores fundamentais que influenciam diretamente na qualidade higiênico-sanitária dos alimentos. É importante salientar que, de acordo com a legislação brasileira, os alimentos ofertados em serviços de alimentação devem estar em boas condições e livres de contaminantes que sejam considerados nocivos à saúde humana (Maia et al., 2011).

Dentre os principais contaminantes de alimentos estão as bactérias: Salmonella sp., aeróbios mesófilos, aeróbios psicrotróficas e fungos (bolores e leveduras), podendo contaminar o alimento de forma intrínseca e extrínseca favorecendo o crescimento microbiano (Porte \& Maia, 2001). Estes contaminantes são responsáveis pela maioria dos surtos de DTA, sendo os principais riscos à segurança alimentar, podendo multiplicar-se rapidamente se o alimento não estiver nas condições ideais de armazenamento e conservação. Por isso a importância do controle higiênico-sanitário para que o alimento não tenha perdas nutricionais e para que as condições inadequadas não favoreçam o crescimento de contaminantes prejudiciais à saúde humana (Brasil, 2004).

Portanto, verificar o local de armazenamento e o transporte dos alimentos é fundamental, principalmente aqueles congelados e com a vida útil curta, pois, se não são armazenados ou manipulados adequadamente podem perder sua qualidade, podendo ser perigoso para consumo humano. Durante sua manipulação e processamento, a contaminação microbiana pode afetar diretamente as características físico-químicas dos alimentos levando a sua deterioração, bem como causar infecções e 
intoxicações, tornando-se inseguros para a população (Marins, Tancredi \& Gemal, 2014).

Frente ao exposto, o presente estudo teve como objetivo avaliar a qualidade higiênico-sanitária do local de armazenamento de alimentos de embarcações e verificar a qualidade microbiológica de carnes, peixes e frangos transportados em barcos que fazem a rota Coari/Amazonas/Brasil - Manaus/Amazonas/Brasil.

\section{Metodologia}

Trata-se de uma pesquisa descritivo-exploratória, de abordagem quali-quantitativa, dividida em duas etapas, realizada no Município de Coari, localizado a 363 km da cidade de Manaus, na região central do Estado do Amazonas (IBGE, 2010). A primeira etapa consistiu em avaliar as condições gerais de manuseio e armazenamento dos alimentos e a segunda, laboratorial, que objetivou identificar os principais agentes patogênicos relacionados às DTA.

O município de Coari atualmente possui 13 barcos para transporte de cargas e passageiros, sendo 11 com aportação fixa na cidade de Tefé (ou outras cidades) e 2 que pertencem ao município. A seleção da amostra para este estudo exploratório preliminar ocorreu por conveniência e incluiu dois barcos que saíram de Coari no sentido capital. A coleta de dados ocorreu entre os meses de novembro e dezembro de 2019, no momento do embarque de passageiros, nas embarcações ancoradas no município de Coari.

A primeira etapa, de avaliação das condições de armazenamento dos alimentos de cada embarcação selecionada, foi realizada por meio de um checklist adaptado da RDC 275 - 2002 (Silva, 2017) e foram avaliados os seguintes aspectos: a estrutura interna do local, o nível de conhecimento dos manipuladores com relação ao armazenamento adequado, condições de higiene gerais, controle de vetores, validade dos equipamentos e a utilização de equipamentos de proteção individual.

Para a realização da segunda etapa, de identificação dos principais patógenos presentes nos alimentos, foram coletadas amostras de 250 a $500 \mathrm{~g}$ de frango, peixe e carne vermelha armazenadas sob refrigeração durante todo o trajeto da viagem e que posteriormente seriam preparados e servidos para passageiros e tripulantes.

Após a coleta, as amostras foram acondicionadas em sacos plásticos esterilizados, identificadas por numeração de acordo com a embarcação, mantidas dentro de embalagens, armazenadas dentro de bolsas térmicas e transportadas até o Laboratório de Microbiologia do Instituto de Saúde e Biotecnologia - Universidade Federal do Amazonas - campus Coari, onde foram mantidas sob refrigeração a $-18{ }^{\circ} \mathrm{C}$ até o momento das análises.

Para as análises microbiológicas, as embalagens contendo as amostras foram submetidas à assepsia com álcool 70\% e, em seguida, uma fração de $25 \mathrm{~g}$ de cada amostra foi separada e transferida para um frasco tipo Erlenmeyer contendo $225 \mathrm{~mL}$ de água peptonada tamponada (Buffered Peptone Water) esterilizada (diluição 10-1) na autoclave, seguido de homogeneização sob agitação em incubadora (SL 222, SOLAB) por 2 horas a 160 RPM. Após esse período, foi realizada a diluição seriada até 10-6 com plaqueamento utilizando a Técnica de Spread Plate (Espalhamento em Placa). As placas foram então incubadas em estufa bacteriológica de acordo com o método proposto para cada microrganismo testado, 24 - 48 h a $37^{\circ} \mathrm{C}$ para bactérias e 3 5 dias para bolores e leveduras (Salfinger \& Tortorello, 2015). Todas as amostras foram analisadas em sua totalidade em um prazo máximo de sete dias após a coleta.

As análises microbiológicas foram realizadas em triplicatas e incluíram grupos de micro-organismos identificadores de qualidade e de segurança: bactérias mesófilas aeróbias, bactérias psicrotróficas, coliformes totais, termotolerantes. As Análises seguiram a metodologia da American Public Health Association (APHA), descritas na $5^{\text {a }}$ edição do Compedium of Foods (Brasil, 2019) de acordo com os Valores Máximos Permitidos (VMP) da legislação vigente RDC 331/2019 e Instrução Normativa n 60/2019 (Marques et al., 2011. Após as análises, os micro-organismos foram submetidos à contagem das colônias com auxílio de uma lupa e um contador de colônias, sendo posteriormente calculado o número de UFC/g. Os coliformes totais e termotolerantes foram determinados por Números Mais Prováveis - NMP/g. Quanto à Salmonella, foi 
analisada ausência/presença.

Os dados das condições gerais de manuseio e armazenamento obtidos pelo check list foram armazenados e analisados através do programa Excel 2013® (Microsoft Office) e apresentado por meio de estatística descritiva (frequência absoluta e relativa). Os dados microbiológicos foram apresentados por meio das médias das triplicatas e comparados com os Valores Máximos Permitidos (VMP) da legislação vigente RDC 331/2019 e Instrução Normativa nº 60/2019 (Marques et al., 2011).

\section{Resultados e Discussão}

\section{Aplicação do checklist segundo a RDC 275/02}

Ambos os barcos foram classificados como pertencentes ao grupo 3 (0 a 50\% de atendimento dos itens), conforme a Tabela 1. Dentre os itens avaliados, as maiores frequências de não conformidades referem-se a equipamentos móveis e utensílios $(55,6 \%)$ e produção e transporte $(44,5 \%)$.

Tabela 1. Itens atendidos e não atendidos de acordo com o Checklist segundo a RDC 275 (Silva, 2017) dos dois barcos avaliados. Coari, Amazonas, Brasil.

\begin{tabular}{ccccc}
\hline Itens avaliados & \multicolumn{2}{c}{ BARCO I } & \multicolumn{2}{c}{ BARCO II } \\
\cline { 2 - 5 } & $\begin{array}{c}\text { Itens atendidos } \\
\mathbf{n}(\%)\end{array}$ & $\begin{array}{c}\text { Itens não atendidos } \\
\mathbf{n}(\%)\end{array}$ & $\begin{array}{c}\text { Itens atendidos } \\
\mathbf{n}(\%)\end{array}$ & $\begin{array}{c}\text { Itens não atendidos } \\
\mathbf{n}(\%)\end{array}$ \\
\hline $\begin{array}{c}\text { Edificação e } \\
\text { instalações } \\
\text { Equipamentos } \\
\text { móveis e } \\
\text { utensílios }\end{array}$ & $7(17,5)$ & $33(82,5)$ & $4(9,3)$ & $39(90,7)$ \\
$\begin{array}{c}\text { Manipuladores } \\
\text { Produção e } \\
\text { transporte }\end{array}$ & $2(44,4)$ & $5(55,6)$ & $3(33,3)$ & $6(66,7)$ \\
\hline Total & $5(55,5)$ & $5(71,4)$ & $0(0,0)$ & $7(100)$ \\
\hline
\end{tabular}

Fonte: Autores.

No âmbito da edificação e instalações, o item ventilação e climatização não estava em conformidade devido à ausência de equipamentos que fazem a troca de ar apropriados para prevenção de contaminações e uma estrutura física que aceita a circulação de ar natural, uma vez que existem microrganismos patogênicos que se multiplicam em lugares quentes (Brasil, 2004). Ainda, observou-se a inexistência de registro da higienização, o qual é necessário, pois indicará a condição higiênico-sanitária como reflexo das características do processo empregado (Brasil, 2002).

Em relação aos manipuladores, a não-conformidade encontrada foi referente à carência do registro de capacitação o qual tem por finalidade a determinação do índice de treinamentos executados, periodicidade e forma de aperfeiçoamento repassado aos funcionários. Dessa maneira há risco de pouco aproveitamento de procedimentos operacionais uma vez que não há funcionários com capacitação atualizada, o que prejudica diretamente as habilidades de manter a segurança higiênicosanitária dos alimentos (Brasil, 2002).

A higienização é um processo que requer duas etapas, a primeira etapa é a da limpeza com a retirada das sujidades, e a segunda desinfecção, que reduz, por método físico ou com uso de algum agente químico, o número de micro-organismos nas instalações, equipamentos, móveis e utensílios, diminuindo os riscos de contaminação. A higienização avaliada de acordo com 
a RDC 275/2002 (Silva, 2017) da ANVISA demonstrou inadequações.

As principais causas de falhas de limpeza encontradas foram em equipamentos e bancadas que são utilizadas para cortes e preparo dos alimentos. Essas falhas permitem que resíduos aderidos aos equipamentos e superfícies se transformem em potencial fonte de contaminação para o alimento (Chesca et al., 2003). A detecção e a rápida correção das falhas no processamento dos alimentos, assim como a adoção de medidas preventivas, são fundamentais para o controle de qualidade dos alimentos (Cardoso et al., 2010).

\section{Análise da qualidade microbiológica}

A contagem de microrganismos aeróbios mesófilos dos alimentos analisados variou de 1,2×104 a 8,2x103 (valor máximo de 3,0x106 UFC/g ou ml), no total observaram-se alimentos com contagem superior aos padrões microbiológicos estipulados pela RDC 331/2019 e Instrução Normativa nº 60/2019 (Zorzo et al., 2019). Os microrganismos psicrotróficos foram encontrados nas amostras de carne e peixe do barco I, no barco II não houve presença. Quanto a avaliação de bolores e leveduras, foram encontradas aproximadamente as mesmas quantidades nas amostras de carnes do barco I e II (7x102 UFC) e no barco II esses microrganismos foram encontrados em maior quantidade nas amostras de peixe (8x102 UFC) (Tabela 2).

Tabela 2. Análises microbiológicas das amostras (frango, carne e peixe) coletadas nos dois barcos avaliados, com os seguintes microrganismos: aeróbios mesófilos, aeróbios psicrotróficas, bolores e leveduras, Salmonella sp, coliformes totais e termotolerantes. Coari, Amazonas, Brasil.

\begin{tabular}{|c|c|c|c|c|c|c|}
\hline \multirow{2}{*}{ Microrganismos } & \multicolumn{3}{|c|}{ BARCO I } & \multicolumn{3}{|c|}{ BARCO II } \\
\hline & Frango & Carne & Peixe & Frango & Carne & Peixe \\
\hline $\begin{array}{l}\text { Aeróbios Mesófilos } \\
\text { (UFC**/g) }\end{array}$ & $3,36 \times 10^{4}$ & $1,14 \times 10^{4}$ & $2,4 \times 10^{4}$ & $0,61 \times 10^{4}$ & $0,82 \times 10^{4}$ & $1,2 \times 10^{4}$ \\
\hline Aeróbios & & & & & & \\
\hline $\begin{array}{l}\text { Psicrotróficos } \\
\text { (UFC**/g) }\end{array}$ & - & $1,59 \times 10^{4}$ & $0,5 \times 10^{4}$ & - & - & - \\
\hline $\begin{array}{c}\text { Bolores e } \\
\text { Leveduras }\left(\mathrm{UFC}^{* * / g}\right)\end{array}$ & $3,2 \times 10^{3}$ & $0,7 \times 10^{3}$ & $4,2 \times 10^{3}$ & $1 \times 10^{3}$ & $0,7 \times 10^{3}$ & $0,8 \times 10^{3}$ \\
\hline Salmonella sp. & + & + & + & + & + & + \\
\hline $\begin{array}{c}\text { Coliformes totais } \\
\text { (NMP/g*) }\end{array}$ & $9,3 \times 10^{1}$ & $1,1 \times 10^{4}$ & $1,1 \times 10^{4}$ & $8,1 \times 10^{4}$ & $1,1 \times 10^{4}$ & $2,4 \times 10^{1}$ \\
\hline Coliformes & & & & & & \\
\hline $\begin{array}{c}\text { termotolerantes } \\
\text { (NMP/g*) }\end{array}$ & $7,4 \times 10^{1}$ & $1,1 \times 10^{4}$ & $2,4 \times 10^{1}$ & $3,6 \times 10^{1}$ & $9,3 \times 10^{1}$ & $1,5 \times 10^{1}$ \\
\hline
\end{tabular}

*NMP/g - Número Mais Provável / grama; **UFC (Unidade Formadora de Colônia); Fonte: Autores.

As amostras de alimentos conservados em ambientes inadequados e manuseados de forma incorreta estão predispostas a serem contaminados por diversos microrganismos. Os microrganismos aeróbios mesófilos, apesar de não serem indicadores de segurança pois não estão relacionados a presença de patógenos ou toxinas, podem ser úteis na avaliação da qualidade de alimentos e uma alta carga microbiana desses organismos pode indicar deficiências na sanitização ou falha no controle do processo de preparo, processamento ou armazenamento dos alimentos (Soares et al., 2015). 
Quanto às bactérias psicrotróficas, foram encontradas somente no Barco I e apenas nas amostras de carne e peixe (tabela 2). Essas bactérias do gênero pseudomonas são importantes na deterioração de alimentos principalmente em peixes armazenados sob refrigeração, pois são capazes de metabolizar aminoácidos presentes em peixes e produzir compostos que causam sabor e odor característico (Soares et al., 2011).

Esses dados corroboram com os achados de Soares et al. (2011) e Reis (2020) e em estudo realizado no estado de São Paulo, que relataram altas contagens de aeróbios psicrotróficos em filés de peixes congelados (Oliveira et al., 2008). Considerando que a Organização Mundial de Saúde (OMS) emitiu que doenças veiculadas por alimentos (DVA) são apontadas como grave problema de saúde pública em todo o mundo ressalta-se a importância de que ocorra uma fiscalização para esses indicadores psicrotróficos, com a finalidade de impedir a disseminação de agentes como Salmonella sp. nos alimentos (Brasil, 2018).

Os resultados de bolores e leveduras ficaram entre $1 \times 10^{3}$ e $8 \times 10^{2} \mathrm{UFC} / \mathrm{g}$, os dois barcos mostraram valores semelhantes com relação a carne que apresentou 7x102 UFC/g (Tabela 2). Dados semelhantes foram encontrados em um estudo em que contagens elevadas de bolores e leveduras foram identificadas em $60 \%$ de amostras de carnes moídas comercializadas em Lavras do Estado de Minas Gerais. A ocorrência de bolores toxigênicos e leveduras nos alimentos se torna um risco à saúde, pois há evidências de produção de micotoxinas e alergias alimentares ao mesmo tempo (Brasil, 2017).

Foi encontrado Salmonella sp, nos dois barcos avaliados e em todas as amostras coletadas. Além disso, todos os peixes comprados, embalados e armazenados para a viagem apresentavam condições de conservação inadequadas e, segundo a legislação brasileira, as amostras se encontravam impróprias para o consumo humano por colocar a saúde em risco dos consumidores. A contaminação está associada às condições inadequadas de higiene e conservação dos produtos nos estabelecimentos, pois se encontravam fora de embalagens e em temperaturas elevadas favorecendo a contaminação e sobrevivência dos microrganismos, o que condiz com os resultados supracitados quanto à RDC 275/02.

Esses resultados destacam o alto risco de contaminação por Salmonella e, consequentemente, de que os consumidores desenvolvam sintomas, desde o mais comum que é a diarreia, até agravos como febre tifoide, febres entéricas, enterocolites e, em piores situações, septicemias. A febre tifoide é considerada uma patologia endêmica no Brasil com surtos epidêmicos principalmente nas regiões norte e nordeste do Brasil e inclusive um dos fatores previamente citados na literatura que pode explicar a persistência desse padrão endêmico é a existência de portadores assintomáticos de patógenos, como cozinheiros de navios de longas viagens ao longo dos rios amazônicos (Martins et al., 2015). Nesse contexto não há como saber se o alimento já veio contaminado de outro local ou se a contaminação ocorreu a partir da manipulação e condições de higiene inadequadas do manipulador, o que ressalta a importância de que haja maior fiscalização e atenção quanto a implementação de práticas higiênico-sanitárias adequadas nesse ambiente.

Foram encontradas no barco I valores > 9,3×101 UFC/g de coliformes totais e termotolerantes, no barco II o maior valor foi de 2,4x101 UFC/g. A presença de coliformes totais foi confirmada no estudo realizado em Castanhal - PA, em frangos in natura e demostrou níveis variantes acima de $150 \mathrm{NMP} / \mathrm{g}$ (Guimarães et al., 2003). A afirmação da presença de coliformes termotolerantes nestes alimentos indica que houve contato direto ou indireto com fezes, entretanto a E. Coli não faz parte da microbiota natural de produtos, confirmando que as condições higiênico-sanitárias das amostras analisadas estão inadequadas (Melo et al., 2010).

Sendo assim, não houve muita diferença entre os dois barcos com relação aos resultados no geral, pois os mesmos apresentaram valores similares dos microrganismos analisados. No entanto, a presença de Salmonella sp se destaca, pois dentre os microrganismos analisados é a mais nociva do ponto de vista de riscos à saúde (Neitzke, Roza e Werber, 2017). Entre os alimentos que apresentaram as maiores contagens foram identificadas algumas situações específicas durante a coleta, em que no item armazenamento o alimento não apresentava rotulagem adequada, lacres, e utensílios higienizados, justificando o alto 
grau de contaminação observado.

A legislação define limites para coliformes totais (Melo et al., 2010), porém a contagem foi superior a 9,3x101 nas amostras de frango dos dois barcos, demonstrando uma alta prevalência na contagem. Os coliformes dos gêneros escherichia, citrobacter, enterobacter e klebsiella são microrganismo indicativos de condições higiênico-sanitárias inadequadas, de forma que sua contagem elevada indica possibilidade de má higiene do manipulador, do ambiente e/ou de utensílios, ou ainda de contaminação cruzada.

Um fator limitante do presente estudo foi a quantidade de barcos analisados, assim como o número pequeno de amostras, o que se justifica pelo difícil acesso às embarcações. Vale salientar nesse contexto a importância de que existam versões adaptadas à realidade de armazenamento e preparo de alimentos em embarcações fluviais, como o manual de boas práticas e procedimentos operacionais padronizados de acordo com as normas da RDC 275/02 (Silva, 2017), já que os itens do checklist não são específicos para tais estabelecimentos.

Ainda que seja uma amostra pequena, destaca-se a importância dos resultados encontrados no que diz respeito a carência de informação e cuidados no armazenamento, estrutura e manipulação dos alimentos analisados, o que justifica e ressalta a demanda e importância de mais estudos e análises nessa região para obtenção de dados mais consistentes e embasamento de ações de intervenção, educação e melhorias das condições higiênico-sanitária das embarcações e dos alimentos armazenados e oferecidos aos passageiros, que têm esses barcos como principal meio de transporte intermunicipal.

\section{Conclusão}

Os resultados obtidos apontam que muito ainda precisa ser feito em relação ao cumprimento das normas higiênicossanitárias em barcos utilizados na região Amazônica. O armazenamento dos gêneros refrigerados e das matérias-primas é uma etapa essencial para garantir alimento íntegro, livre de contaminantes de origem física, química e biológica, que sejam de boa aceitação sensorial e de acordo com as necessidades nutricionais e expectativas dos embarcados. O presente estudo mostrou que os alimentos armazenados sob refrigeração, nas embarcações analisadas, possuem uma baixa qualidade microbiológica, podendo gerar riscos ao consumidor e ressalta a demanda por ações de vigilância sanitária visando a identificação de riscos e, principalmente, ações de orientações e educativas, de forma a transmitir aos funcionários envolvidos no preparo desses alimentos, o conhecimento necessário para a estruturação do espaço físico e adesão de práticas higiênico-sanitárias adequadas, visando a qualidade das refeições oferecidas nas embarcações.

\section{Agradecimentos}

A autora KDS recebeu apoio financeiro da UFAM (PIBIC 2019/2020) - PIB-S/0067/2019

\section{Referências}

Brasil. (2019). Constituição (2019). Resolução - RDC No 331, de 23 de dezembro de 2019 nº 96, de 26 de dezembro de 2019. Órgão: Ministério da Saúde/Agência Nacional de Vigilância Sanitária. 249. ed. - Diário Oficial Da União

Brasil. (2017) Ministério Da Saúde, Secretaria De Vigilância Sanitária Em Saúde. Doenças Transmitidas Por Alimentos. $<$ Http://Portalms.Saude.Gov.Br/Saude-De-A-Z/Doencas-Transmitidas-Por-Alimentos>.

Brasil. (2004) Anvisa, Ministério da Saúde, Resolução RDC 216, de 15 de setembro de 2004. Dispõe sobre o Regulamento Técnico de Boas Práticas para Serviços de Alimentação. D.O.U. - Imprensa Nacional

Brasil. (2018) Ministério da Saúde - MS. Surtos de Doenças transmitidas por alimentos no Brasil. <http://portalarquivos2.saude.gov.br/imag es/pdf/2018/julho/02/Apresentacao-Surtos-DTA-Junho-2018.pdf>.

Brasil. (2011). Ministério do Planejamento, Orçamento e Gestão. Instituto Brasileiro de Geografia e Estatística - IBGE. Sinopse do Censo Demográfico: 2010. 
Brasil. (2002) Regulamento Técnico de Procedimentos Operacionais Padronizados aplicados aos Estabelecimentos Produtores/Industrializadores de Alimento e a Lista de Verificação das Boas Práticas de Fabricação em Estabelecimentos Produtores/Industrializadores de Alimentos. Resolução RDC n 275 , de 21 de outubro de 2002 - Imprensa Nacional.

Cardoso, R. C. V, et al. (2010). Avaliação da qualidade microbiológica de alimentos prontos para consumo servidos em escolas atendidas pelo Programa Nacional de Alimentação Escolar. Rev Inst Adolfo Lutz, Salvador, 1-6.

Carmo, G. M. I., et al. (2005). Vigilância epidemiológica das doenças transmitidas por alimentos no Brasil, 1999-2004. Boletim Eletrônico Epidemiológico. <http://portal.saude.gov.br/portal/arquivos/pdf/bol_epi_6_2005_corrigido.pdf>.

Chesca, A. C., et al. (2003). Equipamentos e utensílios de unidades de alimentação e nutrição: um risco constante de contaminação das refeições. Rev Hig Alimentar, 17(114/ 115):20-23.

Guimarães, A. M., et al. (2003). Frequência de enteroparasitas em amostras de alface (Lactuca sativa) comercializadas em Lavras, Minas Gerais. Revista da Sociedade Brasileira de Medicina Tropical, 36(5): 621-3.

Maia, L. G. S., et al. (2011). Variabilidade genética associada à germinação e vigor de sementes de linhagens de feijoeiro comum. Ciência e Agrotecnologia, 35:361-7.

Marins, B. R., Tancredi, R. C. P., \& GemaL, A. L. (2004). Segurança alimentar no contexto da vigilância sanitária: reflexões e práticas. 288 f., Escola Politécnica de Saúde Joquim Venâncio, Rio de Janeiro.

Marques, E. C, et al. (2011). VII Congresso Nacional de Excelência em Gestão, 2011, Rio de Janeiro. Aplicação Do Programa de Pré-requisitos para Garantia da Segurança do Alimento em Barco Pesqueiro.. 1-20.

Martins, M., et al. (2015). Progression of the load of waterborne and intestinal parasitic diseases in the state of amazonas. Revista Da Sociedade Brasileira de Medicina Tropical, 48(Suppl I), 42-54.

Mello, A. G. et al. (2010). Conhecimento dos manipuladores de alimentos sobre boas práticas nos restaurantes públicos populares do Estado do Rio de Janeiro. Brazilian Journal of Food Technology, Campinas, 13(1):60-8.

Neitzke, D. C, Roza, C. R., \& Werber, F. H. (2017). Segurança dos alimentos: contaminação por Salmonella sp. no abate de suínos. Brazilian Journal of Food Technology [online]. 20:e2015063.

Oliveira, M. M. M, Brugnera, D. F, Mendonça, A. T, \& Picolli, R. H. (2008). Condições higiênico-sanitárias de máquinas de moer carne, mãos de manipuladores e qualidade microbiológica da carne moída. Ciência e Agrotecnologia, 32(6):1893-8. 〈http://www.scielo.br/pdf/cagro/v32n6/v32n6a31.pdf>

Porte, A., Maia, L. H. (2001) Alterações fisiológicas, bioquímicas e microbiológicas de alimentos minimamente processados. Boletim do Centro de Pesquisa e Processamento de Alimentos CEPPA, 19(1):105-118.

Reis, R. M., et al. (2020). Occurrence of psychrotrophic microorganisms in ground meat in natura marketed in the city of Manaus, Amazonas. Braz. J. of Develop., 6(6):41750-59.

Salfinger, Y. \& Tortorello, M. L. (2015). Compedium of Methods for Microbiological Examination of Foods, American Public Health Association (APHA).

Silva, N. (2017). Manual de métodos de análise microbiológica de alimentos e água. Blucher.

Soares, K. M. P., Silva, J. B. A., Souza, L B., Mendes, C. G., Abrantes, M. R., Campelo, M. C. S., Souza, A. S. (2015). Qualidade microbiológica de carne bovina comercializada na forma de bife. Revista Brasileira de Ciência Veterinária, [s.1.], 22(3-4):206-10.

Soares, M. V et al. (2017). Transporte fluvial: estreitamento as distâncias econômicas e socias entre mocambo do Arari e cidade de Parintins/AM. 20 f. TCC (Graduação) - Curso de Licenciatura em Geografia, Cesp-UEA, Parintins.

Soares, V. M., Pereira, J. G., Izidoro, T. B., Martins, O. A., Pinto, J. P. A. N., \& Biondi, G. F. (2011). Qualidade microbiológica de filés de peixe congelados distribuídos na cidade de Botucatu - SP. UNOPAR Científica Ciências Biológicas e da Saúde, 13(2):85-8.

Zorzo, C. et.al. (2019). Aspecto higiênico e sanitário da carne moída comercializada no município de Sinop, Mato Grosso. PUBVET - Medicina Veterinária e Zootecnia. 13(11)1-7. 